\title{
Microembolic Signals in Patients with Systemic Lupus Erythematosus
}

\author{
Mahmoud Reza Azarpazhooh, Naghmeh Mokhber, Elias Orouji, \\ Brian R. Chambers, Mohammad Reza Hatef, Zahra Rezaieyazdi, Sima Sedighi, \\ Mohsen Foroghipoor, Arash Velayati, Morteza Modares Gharavi
}

\begin{abstract}
Introduction: Central nervous system (CNS) involvement is a common and less understood aspect of systemic lupus erythematosus (SLE). Microembolic signals (MES) have been reported in SLE. We conducted a prospective study to evaluate the frequency of MES among patients with CNS involvement and those without. The main aim of the study is to clarify the pathophysiology of the CNS involvement in SLE. Methods and Materials: Sixty eight patients with a diagnosis of SLE (60 females, 8 males) participated in the study. Both middle cerebral arteries were monitored using transcranial Doppler for 60 min to detect MES. All cases underwent neurology and psychiatry assessments. Results: MES were detected in 7/68 patients (10.3\%) with the mean number of 3.5 per hour. MES were significantly higher in patients with CNS involvement $(6 / 24,25 \%)$ than those without $(1 / 44,2.2 \%)(\mathrm{P}=0.006)$. SLE disease activity index, duration of disease, plaque formation, intima-media thickness, and antiphospholipid antibodies were not associated with MES. MES were more frequent in patients receiving Aspirin and/or Warfarin ( $\mathrm{p}=0.02)$. Conclusions: MES may be a predictor for CNS involvement in SLE patients at risk for neuropsychiatric syndromes. Cerebral embolism may be implicated in the pathophysiology of neuropsychiatric SLE.
\end{abstract}

RÉSUMÉ: Signaux microemboliques chez les patients atteints de lupus érythémateux aigu disséminé. Contexte : L'atteinte du système nerveux central (SNC) est fréquente dans le lupus érythémateux aigu disséminé (LEAD), mais cet aspect de la maladie est mal compris. Des signaux microemboliques (SME) ont été décrits dans le LEAD. Nous avons effectué une étude prospective pour évaluer la fréquence des SME chez les patients qui avaient une atteinte du SNC et chez ceux qui n'en avaient pas. Le but principal de l'étude était de déterminer la physiopathologie de l'atteinte du SNC dans le LEAD. Méthodes et matériels : Soixante-huit patients chez qui un diagnostic de LEAD avait été posé (60 femmes et 8 hommes) ont participé à l'étude. Les deux artères cérébrales moyennes ont été étudiées pendant 60 minutes au moyen du Doppler transcrânien afin de détecter les SME. Tous les patients ont subi une évaluation neurologique et psychiatrique. Résultats : Des SME ont été détectés chez 7 des 68 patients (10,3\%) et leur nombre moyen était de 3,5 par heure. Le nombre de SME était significativement plus élevé chez les patients qui présentaient une atteinte du SNC $(6 / 24$, soit $25 \%)$ que chez ceux qui n'en présentaient pas $(1 / 44$, soit 2,2\%) (p = 0,006). L'indice d'activité de la maladie, la durée de la maladie, la formation de plaques, l'épaisseur de l'intima-média et les anticorps antiphospholipides n'étaient pas associés aux SME. Les SME étaient plus fréquents chez les patients qui recevaient de l'aspirine et/ou de la warfarine $(\mathrm{p}=0,02)$. Conclusions : Les SME peuvent être un signe prédictif d'atteinte du SNC chez les patients atteints de LEAD qui sont à risque de syndromes neuropsychiatriques (NP). L'embolie cérébrale pourrait être en cause dans la physiopathologie du LEAD-NP.

Can. J. Neurol. Sci. 2010; 37: 371-375

Central nervous system involvement is one of the most serious complications of systemic lupus erythematosus (SLE). More than half of patients with SLE demonstrate major psychiatric and neurological disorders ${ }^{1-4}$. The most common manifestations of neuropsychiatric SLE (NP-SLE) include seizures, psychosis, brainstem dysfunction, stroke and cognitive impairment $^{2}$.

Despite the numerous previous studies $^{5-8}$, the exact pathogenesis of disease is not completely understood, and therefore its recognition and treatment remains a major diagnostic and therapeutic challenge. The possible mechanisms include vasculopathy, autoantibody production, immunologically mediated thromboembolism and systemic inflammation. Antiphospholipid (aPL) antibodies, hyperhomocysteinaemia, cardiac valve pathology and other vascular risk factors can also increase the risk of stroke $e^{4,9-14}$.
Microembolic signals (MES) in major intracranial cerebral arteries can be detected using transcranial Doppler (TCD) sonography. Although MES are usually not associated with immediate focal neurological symptoms, there is growing

From the Department of Neurology (MRA, MF, AV), Department of Rheumatology (ZR, SS), Ghaem Medical Center, Department of Psychiatry (NM, MMG), Avicenna Hospital, Department of Rheumatology (MRH), Emam Reza Hospital, Mashhad University of Medical Sciences (EO), Mashhad, Iran; Austin Health (BRC), National Stroke Research Institute, Victoria, Australia.

Received September 14, 2009. Final Revisions Submitted November 11, 2009 Correspondence to: Mahmoud Reza Azarpazhooh, Department of Neurology, Ghaem Medical Center, Mashhad University of Medical Science, Taghi Abad Square, Mashhad, Iran. 
evidence that ongoing and generalized occurrence of MES may lead to deterioration of cognitive function ${ }^{13}$. Microembolic signals may also be an indirect marker of stroke risk in patients with carotid stenosis ${ }^{15}$. A few studies have reported MES in SLE and its relation with NP-SLE ${ }^{16-19}$. This study was designed to compare MES in NP-SLE and SLE without neuropsychiatric manifestations (non-NP-SLE). The main aim of the study was to clarify the pathophysiology of the CNS involvement in NP-SLE.

\section{SubJects ANd Methods}

Sixty-eight patients with a diagnosis of SLE were recruited and investigated from December 1, 2006, through March 15, 2007. These patients were cases with SLE referred to the rheumatology clinics of Ghaem Medical Center and Emam Reza Hospital of Mashhad University of Medical Sciences from all through the Khorasan province, in north-east Iran. Written consent forms were obtained from all subjects before investigation and this study was approved by the ethics committee of the Mashhad University of Medical Sciences. Patients fulfilled the revised 1982 criteria of the American College of Rheumatology (ACR) for SLE, developed for the purpose of identifying patients in clinical studies. The diagnosis of SLE is based on the presence of 4 or more of 11 criteria, serially or simultaneously, during any interval of observation ${ }^{20}$.

Patients with poor temporal windows, and other possible sources of emboli including recent cardiac surgery, recent myocardial infarction, and valvular heart disease were excluded. All patients underwent detailed examination, including review of medical records, neurologic examination, neuropsychological testing, and cardiology evaluation including physical examination, electrocardiography, and trans-thoracic echocardiography. Neuropsychiatric syndromes were classified according to the standardized ACR nomenclature and case definitions ${ }^{21}$. Disease activity was quantified using the SLE Disease Activity Index (SLEDAI) ${ }^{22}$. Demographic data as well as disease duration, drug history, and aPL antibodies were also recorded. Cognitive functions were evaluated using three neuropsychological tests, Mini-mental State Examination (MMSE), Bender-Gestalt test and Block Design subset from Wechsler Adult Intelligence Scale (WAIS-R). Mini-mental State Examination is a brief cognitive screening test for evaluating orientation, language, short-term memory, construction, and attention. Bender-Gestalt test was administered to evaluate visual-motor functioning and visual perceptual skills. Executive ability and right hemisphere functions were assessed using Block Design (a non verbal IQ ability) a subset of WAIS-R ${ }^{23}$. Depression and anxiety were assessed on clinical interview. After a thorough evaluation patients were divided into two groups: NP-SLE and non-NP-SLE according to criteria previously described by the ACR Ad Hoc Committee ${ }^{21}$.

Atherosclerotic plaques were investigated by ultrasound examination of both carotid arteries using a high-resolution ultrasound scanner (Medison, SA8000EX) equipped with a linear-array transducer. The maximum intima-media thickness in common and internal carotid arteries was measured on frozen B-mode images. Like our previous MES detection study ${ }^{24}$, TCD evaluation was performed using an Atys TCD ultrasonographic instrument (Atys Medical, St. Genislaval, France) equipped with a $2 \mathrm{MHz}$ probe and Spencer head frame. Both MCAs were monitored for 60 min using the Bilateral Multigate mode. The results were reviewed off-line, and MES were defined as being

Table 1: Clinical and paraclinical characteristics of patients with NP-SLE and non-NP-SLE

\begin{tabular}{l|c|c|c}
\hline & NP-SLE (n=24) & non-NP-SLE (n=44) & P value \\
\hline Female & $21 / 24(87.5 \%)$ & $39 / 44(88.6 \%)$ & 1.0 \\
\hline Age (Years) & $30.8 \pm 9.9$ & $28.2 \pm 11.0$ & 0.33 \\
\hline Disease duration (Years) & $4.8 \pm 5.3$ & $4.1 \pm 5.0$ & 0.85 \\
\hline Use of Aspirin and Warfarin & $5 / 24(20.8 \%)$ & $8 / 44(18.2 \%)$ & 1.0 \\
\hline SLEDAI* (mean) & $9.2 \pm 7.5$ & $8.6 \pm 7.0$ & 0.71 \\
\hline aPL antibodies** & $2 / 17(8.3 \%)$ & $3 / 40(6.8 \%)$ & 0.62 \\
\hline Plaque formation & $3 / 24(12.5 \%)$ & $2 / 43(4.5 \%)$ & 0.34 \\
\hline IMT $\dagger$ Right CCA (mm) & $0.37 \pm 0.06$ & $0.40 \pm 0.10$ & 0.27 \\
\hline IMT Right ICA (mm) & $0.37 \pm 0.08$ & $0.37 \pm 0.07$ & 0.63 \\
\hline IMT Left CCA (mm) & $0.39 \pm 0.09$ & $0.40 \pm 0.07$ & 0.75 \\
\hline IMT Left ICA (mm) & $0.38 \pm 0.10$ & $0.38 \pm 0.07$ & 0.96 \\
\hline MES $\$$
\end{tabular}

* SLE Disease Activity Index; **Antiphospholipid antibodies; $\uparrow:$ Intima-media thickness; $\ddagger$ : Microembolic signals 


\begin{tabular}{lccc}
$\begin{array}{l}\text { Table 2: Clinical and paraclinical characteristics of patients with and } \\
\text { microembolic signals (MES) }\end{array}$ & without \\
\hline & $7 / 7(100 \%)$ & $53 / 61(86.9 \%)$ & 0.58 \\
\hline Female & $25.8 \pm 7.8$ & $29.4 \pm 10.8$ & 0.42 \\
Age (Years) & $4.7 \pm 5.5$ & $4.3 \pm 5.1$ & 0.84 \\
Disease duration(Years) & $4 / 7(57.1 \%)$ & $9 / 61(14.8 \%)$ & 0.02 \\
Use of Aspirin and Warfarin & & \\
SLEDAI* (mean) & $11.5 \pm 7.8$ & $8.5 \pm 7.0$ & 0.35 \\
aPL antibodies** & $1 / 4(25 \%)$ & $4 / 53(7.5 \%)$ & 0.31 \\
Plaque & $1 / 7(14.3 \%)$ & $4 / 59(6.7 \%)$ & 0.434 \\
IMT $\dagger$ Right CCA(mm) & $0.39 \pm 0.09$ & $0.343 \pm 0.05$ & 0.47 \\
IMT Right ICA (mm) & $0.34 \pm 0.05$ & $0.380 \pm 0.78$ & 0.232 \\
IMT Left CCA (mm) & $0.38 \pm 0.12$ & $0.40 \pm 0.07$ & 0.631 \\
IMT Left ICA (mm) & $0.38 \pm 0.12$ & $0.38 \pm 0.08$ & 0.941
\end{tabular}

* SLE Disease Activity Index; **Antiphospholipid antibodies; $†$ : Intima-media thickness

random, unidirectional, high intensity, and short duration signals, with an associated characteristic chirping sound ${ }^{25-26}$.

The Fisher's exact test and independent t test were used to analyze the relationship between the presence of MES, and neuropsychiatric syndrome as well as other demographic data. $\mathrm{p}<0.05$ was considered as significant.

\section{Results}

During the study period, 68 patients who fulfilled the revised 1982 criteria of the ACR for SLE were recruited ${ }^{20}$. Based on neurology examination, psychiatric interview, and neuropsychology testing, 24 patients $(35 \%)$ were classified as NP-SLE and 44 patients $(65 \%)$ as non-NP-SLE. The average age of all patients (mean \pm standard deviation) was $29.1 \pm 10.7$ years (range 15-58), with disease duration of $4.3 \pm 5.1$ (range 2 months20 years). There were more females than males ( $88 \%$ vs. $12 \%$ ). Five out of 66 cases $(7.4 \%)$ had non stenosing atherosclerotic plaque in carotid arteries. Eight cases used Aspirin alone, 4 Warfarin alone, and 13 (19.1\%) Aspirin and Warfarin. There were no differences between NP-SLE and non-NP-SLE groups with respect to age, sex, SLE Disease Activity Index, duration of disease, use of Aspirin and/or Warfarin, plaque formation, IMT, and aPL antibodies (Table 1).

Cognitive evaluation using the MMSE revealed 12 patients with scores $\leq 24$ score consistent with moderate cognitive impairment. Thirteen patients had WAIS-R scores $\leq 20$ and 14 patients had Bender-Gestalt scores $\geq 6$.
Microembolic signals were detected in 7/68 (10.3\%) patients comprising 6/24 in the NP-SLE group, and 1/44 in the non-NPSLE group $(\mathrm{p}=0.006)$. The mean number of MES per hour was 3.5 (range 1-6). In the 7 patients with MES and 61 without MES (Table 2) the only variable significantly associated with detection of MES was treatment with Aspirin and/or Warfarin $(\mathrm{p}=0.02)$.

\section{Discussion}

Neuropsychiatric systemic lupus erythematosus is a common but poorly understood form of SLE ${ }^{5-8}$. The mechanism of NPSLE is complex and likely to be multifactorial. In this study, we found MES in $10.3 \%$ of patients, which was similar to some previous studies ${ }^{17,19}$, although less than in Kumral's et al, study, where MES were found in $20.7 \%$ of cases ${ }^{18}$.

The detection of MES provides important pathophysiological information in a variety of disorders, but their clinical importance and possible therapeutic implications is still the subject of discussion ${ }^{15}$. Although MES have been reported in SLE, their exact role in the pathogenesis of NP-SLE is uncertain. Dahl et al, found an association between MES and cerebral infarcts ${ }^{19}$. In our study the detection of MES was significantly higher in NP-SLE $(\mathrm{P}=0.006)$, raising the possibility that cerebral microemboli may have a role in NP-SLE pathogenesis.

The origin of MES in SLE is also a matter of debate. Vasculitis of the small vessels, hypercoagulability, and early atherosclerosis are some of the proposed mechanisms. Despite the high risk for subclinical atherosclerosis in $\mathrm{SLE}^{27}$, there was 
no relation between MES and carotid duplex findings or vascular risk factors ${ }^{19}$. In the study of Kron et $\mathrm{al}^{17}$, heart valve repair or replacement was the only significant factor associated with MES. They could not find any association between MES and carotid duplex abnormalities and postulated that MES may originate from the heart ${ }^{17}$. However, we did not include any cases with valve pathology in our study. Although MES have been reported in patients with aPL antibodies $16,18,28,29$, no association was found in Dahl's and Kron's studies ${ }^{19,17}$. In our study, plaque formation, and aPL antibodies were more frequent in the MES-Positive group, but these failed to reach statistical significance. The SLE disease activity index and disease duration were also higher in the MES-positive group; however, these also were not statistically significant. We believe that the mechanism of MES production is likely to be as complex as NP-SLE.

The detection of MES in patients with SLE could potentially aid the selection of antithrombotic treatment after acute stroke, determine oral anticoagulant intensity and assess the efficacy of therapeutic strategies for the secondary prevention of stroke. Antithrombotic agents reduce the occurrence of MES and the effect of antithrombotic agents on MES may serve as a marker for their efficacy in preventing TIA and stroke recurrence ${ }^{15}$. Kron et al, ${ }^{17} \mathrm{did}$ not find any significant association between MES and Aspirin usage. Surprisingly, we found that MES were more likely to be detected in patients receiving Aspirin and/or Warfarin $(\mathrm{p}=0.02)$. This may be a chance observation due to our small sample size, or those patients prescribed aspirin or warfarin may have had clinical findings or diagnostic results predicting a higher rate of thrombo-embolic events.

The small sample size is a limitation of our study. We did not perform all the neuropsychiatric tests proposed by the ACR for SLE, and therefore it is possible some cases of NP-SLE were not diagnosed. We did not evaluate silent stroke by brain MRI and sub-clinical cardiac disease by trans-esophageal echocardiography.

\section{CONCLUSION}

We have found an association between presence of MES and NP-SLE. However, microembolism cannot explain all cases of NP-SLE. Further studies are needed to clarify the role of MES in the pathophysiology of NP-SLE, their origin, and the role of preventive antithrombotic treatment.

\section{ACKNOWLEDGEMENTS}

This study was supported by a grant from the vice chancellor for research at Mashhad University of Medical Sciences (No. 6083). The project was presented as a thesis for completion of M.D. degree by Dr. Elias Orouji. We would like to acknowledge Dr. Mohammad Khajehdaloee, and Mr. Amir Abass Azarian for their help in data analysis, Ms. Khaniani for her assistance during TCD monitoring and Ms. Shahraki for performing the neuropsychological tests.

\section{REFERENCES}

1. Sibley JT, Olszynski WP, Decoteau WE, Sundaram MB. Incidence and prognosis of central nervous system disease in systemic lupus erythematosus. J Rheumatol. 1992;19(1):47-52.
2. Ainiala H, Loukkola J, Peltola J, Korpela M, Hietaharju A. The prevalence of neuropsychiatric syndromes in systemic lupus erythematosus. Neurology. 2001;57(3):496-500.

3. Hanly JG, Walsh NM, Sangalang V. Brain pathology in systemic lupus erythematosus. J Rheumatol. 1992;19(5):732-41.

4. Omdal R. Some controversies of neuropsychiatric systemic lupus erythematosus. Scand J Rheumatol. 2002;31(4):192-7.

5. Harris EN, Pierangeli S. Antiphospholipid antibodies and cerebral lupus. Ann NY Acad Sci. 1997;823:270-8.

6. Pope JM, Canny CL, Bell DA. Cerebral ischemic events associated with endocarditis, retinal vascular disease, and lupus anticoagulant. Am J Med. 1991;909(3):299-309.

7. Steinlin MI, Blaser SI, Gilday DL, Eddy AA, Logan WJ, Laxer RM, et al. Neurologic manifestations of pediatric systemic lupus erythematosus. Pediatr Neurol. 1995;13(3):191-7.

8. Sabbadini MG, Manfredi AA, Bozzolo E, Ferrario L, Rugarli C, Scorza R, et al. Central nervous system involvement in systemic lupus erythematosus patients without overt neuropsychiatric manifestations. Lupus. 1999;8(1):11-19.

9. Tam LS, Fan B, Li EK, Thomas GN, Yim SF, Haines CJ, et al. Patients with systemic lupus erythematosus show increased platelet activation and endothelial dysfunction induced by acute hyperhomocysteinemia. J Rheumatol. 2003;30(7):1479-84.

10. Devinsky O, Petito CK, Alonso DR. Clinical and neuropathological findings in systemic lupus erythematosus; the role of vasculitis, heart emboli and thrombotic thrombocytopenic purpura. Ann Neurol. 1988;23(4):380-4.

11. Krause I, Lev S, Fraser A, Blank M, Lorber M, Stojanovich L, et al. Close association between valvar heart disease and central nervous system manifestations in the antiphospholipid syndrome. Ann Rheum Dis. 2005;64(10):1490-3.

12. Love PE, Santoro SA. Antiphospholipid antibodies: anticardiolipin and the lupus anticoagulant in systemic lupus erythematosus (SLE) and in non-SLE disorders. Prevalence and clinical significance. Ann Intern Med. 1990;112(2):682-98.

13. Petri M. Thrombosis and systemic lupus erythematosus: the Hopkins Lupus Cohort perspective. Scand J Rheumatol. 1996;25 (4):191-3.

14. Petri M, Roubenoff R, Dallal GE, Nadeau MR, Selhub J, Rosenberg IH. Plasma homocysteine as a risk factor for atherothrombotic events in systemic lupus erythematosus. Lancet. 1996;348 (9035):1120-4

15. Azarpazhooh MR, Chambers BR. Clinical application of transcranial Doppler monitoring for embolic signals. J Clin Neurosci. 2006;13(8):799-810.

16. Rademacher J, Söhngen D, Specker C, Janda I, Sitzer M. Cerebral microembolism, a disease marker for ischemic cerebrovascular events in the antiphospholipid syndrome of systemic lupus erythematosus? Acta Neurol Scand. 1999;99(6):356-61.

17. Kron J, Hamper UM, Petri M. Prevalence of cerebral microemboli in systemic lupus erythematosus: transcranial Doppler. J Rheumatol. 2001;28(10):2222-5.

18. Kumral E, Evyapan D, Keser G, Kabasakal Y, Oksel F, Aksu K, et al. Detection of microembolic signals in patients with neuropsychiatric lupus erythematosus. Eur Neurol. 2002;47(3): $131-5$.

19. Dahl A, Omdal R, Waterloo K, Joakimsen O, Jacobsen EA, Koldingsnes W, et al. Detection of cerebral embolic signals in patients with systemic lupus erythematosus. J Neurol Neurosurg Psychiatry. 2006; 77(6):774-9

20. Tan EM, Cohen AS, Fries JF, Masi AT, McShane DJ, Rothfield NF, et al. The 1982 revised criteria for the classification of systemic lupus erythematosus. Arthritis Rheum. 1982; 25(11):1271-7.

21. ACR Ad Hoc Committee on Neuropsychiatric Lupus Nomenclature. The American College of Rheumatology nomenclature and care definitions for neuropsychiatric lupus syndromes. Arthritis Rheum. 1999; 42: 599-608.

22. Bombardier C, Gladman DD, Urowitz MB, Caron D, Chang CH. Derivation of the SLEDAI: a disease activity index for lupus patients. Arthritis Rheum. 1992;35(6):630-40.

23. Groth-Marnat G. Handbook of psychological assessment, 4th ed. Hoboken, New Jersey: John Wily and Sons, Inc.; 2003. 
24. Azarpazhooh MR, Velayati A, Chambers BR, Mashhadi Nejad H, Sasan Nejad P. Microembolic signals in subarachnoid hemorrhage. J Clin Neurosci. 2009;16(3):390-3.

25. Consensus Committee of the Ninth International Cerebral Hemodynamic Symposium. Basic identification criteria of Doppler microembolic signals. Stroke. 1995;26:1123.

26. Markus HS, Ackerstaff R, Babikian V, Bladin C, Droste D, Grosset $\mathrm{D}$, et al. Intercenter agreement in reading Doppler embolic signals. A multicenter international study. Stroke. 1997;28(7): 1307-10.
27. Roman MJ, Moeller E, Davis A, Paget SA, Crow MK, Lockshin $\mathrm{MD}$, et al. Preclinical carotid atherosclerosis in patients with rheumatoid arthritis. Ann Intern Med. 2006; 144(4):249-56.

28. Specker C, Rademacher J, Söhngen D, Sitzer M, Janda I, Siebler M, et al. Cerebral microemboli in patients with antiphospholipid syndrome. Lupus. 1997;6(8):638-44.

29. Sitzer M, Söhngen D, Siebler M, Specker C, Rademacher J, Janda I, et al. Cerebral microembolism in patients with Sneddon's syndrome. Arch Neurol. 1995;52(3): 271-5. 